\title{
An agenda for integrated system-wide interdisciplinary agri-food research
}

\author{
Peter Horton ${ }^{1,2}$ (D) - Steve A. Banwart ${ }^{3,4}$ - Dan Brockington ${ }^{5}$ - Garrett W. Brown ${ }^{6}$. \\ Richard Bruce $^{1,7}$ • Duncan Cameron ${ }^{8}$ - Michelle Holdsworth ${ }^{9}$ - S. C. Lenny Koh ${ }^{7,10}$ • \\ Jurriaan Ton ${ }^{8} \cdot$ Peter Jackson $^{3}$
}

Received: 3 June 2016 / Accepted: 2 January 2017 / Published online: 16 February 2017

(C) The Author(s) 2017. This article is published with open access at Springerlink.com

\begin{abstract}
This paper outlines the development of an integrated interdisciplinary approach to agri-food research, designed to address the 'grand challenge' of global food security. Rather than meeting this challenge by working in separate domains or via single-disciplinary perspectives, we chart the development of a system-wide approach to the food supply chain. In this approach, social and environmental questions are simultaneously addressed. Firstly, we provide a holistic model of the agri-food system, which depicts the processes involved, the principal inputs and outputs, the actors and the external influences, emphasising the system's interactions, feedbacks and complexities. Secondly, we show how this model necessitates a research programme that includes the
\end{abstract}

Peter Horton

p.horton@sheffield.ac.uk

1 Grantham Centre for Sustainable Futures, University of Sheffield, Sheffield, UK

2 Department of Molecular Biology and Biotechnology, University of Sheffield, Sheffield, UK

3 Department of Geography, University of Sheffield, Sheffield, UK

4 Present address: School of Earth and Environment, University of Leeds, Leeds, UK

5 Sheffield Institute for International Development, University of Sheffield, Sheffield, UK

6 Department of Politics, University of Sheffield, Sheffield, UK

7 Management School, University of Sheffield, Sheffield, UK

8 Plant Production \& Protection (P3) Centre, Department of Animal and Plant Sciences, University of Sheffield, Sheffield, UK

9 School of Health and Related Research, University of Sheffield, Sheffield, UK

10 Advanced Resource Efficiency Centre, University of Sheffield, Sheffield, UK study of land-use, crop production and protection, food processing, storage and distribution, retailing and consumption, nutrition and public health. Acknowledging the methodological and epistemological challenges involved in developing this approach, we propose two specific ways forward. Firstly, we propose a method for analysing and modelling agri-food systems in their totality, which enables the complexity to be reduced to essential components of the whole system to allow tractable quantitative analysis using LCA and related methods. This initial analysis allows for more detailed quantification of total system resource efficiency, environmental impact and waste. Secondly, we propose a method to analyse the ethical, legal and political tensions that characterise such systems via the use of deliberative fora. We conclude by proposing an agenda for agri-food research which combines these two approaches into a rational programme for identifying, testing and implementing the new agri-technologies and agri-food policies, advocating the critical application of nexus thinking to meet the global food security challenge.

Keywords Food security $\cdot$ Land use $\cdot$ Resource management . Crop production - Food production - Food sales $\cdot$ Consumer practice $\cdot$ Nutrition $\cdot$ Public health $\cdot$ Life cycle assessment . Food justice $\cdot$ Agri-food research

\section{Introduction}

Conventionally defined as when 'all people, at all times, have physical, social and economic access to sufficient, safe and nutritious food that meets their dietary needs and food preferences for an active and healthy life' (FAO 2002), food security is generally acknowledged to be one of the 'grand challenges' currently facing humanity. The challenge is neatly summarised as a 'perfect storm' of converging global issues (Beddington 
2010 ) as the world's population is set to reach 9.6 billion by 2050 (UN 2013) with a quadrupling in the global economy, a doubling in the demand for food and fuel, and a more than $50 \%$ increase in the demand for clean water (Foresight 2011). This challenge is amplified by the need to stay within the safe operating space for humanity and avoid catastrophic climate change (Rockström et al. 2009). The 5th IPCC report (IPCC 2014) notes the weight of studies that predict a decline in agricultural production by 2050 due to climate change impacts and summarises the substantial risk evidence that Europe, Africa, Asia and Central and South America will experience water shortages driven by changing climate, leading to declining agricultural production and increased rural poverty during the coming few decades.

We acknowledge the long track-record of work establishing the links between food security and global environmental change (summarised by Ingram et al. 2012) and the numerous research programmes, including the Rural Economy and Land Use (RELU) and Global Food Security (GFS) initiatives in the UK, that have sought to address these issues through coordinated interdisciplinary research. While many have emphasised the need to focus on increasing crop yields and improving the efficiency of agricultural production through 'sustainable intensification' (Garnett et al. 2013), it is increasingly recognised that the insights of political and social science are as important as technological advances in agri-food science. As Ingram et al. conclude: 'scientific and policy attention has ... mainly focused on increasing total production through increases in yield [which] arguably risks ignoring people's anxieties about sustaining access to food ... and the other nutritional, social and economic aspects of food security' (Ingram et al. 2013). Thus, we conclude that achieving adequate food production whilst ensuring environmental and economic sustainability and promoting human health and social equity will require changes in all parts of the food system.

Following the work of Soussana (2014) and a recent comprehensive report from the US National Academies (IOM and NRC 2015), this paper charts the development of an integrated approach to agri-food research, working across the food supply chain rather than isolated researchers working on separate parts of the problem. It demonstrates the need for interdisciplinary research that addresses the operation of both environmental and social systems (and their effective integration). While many others are working on these challenges, including the governance and management issues that arise when working across scales (Cash et al. 2006), this paper outlines an interdisciplinary and system-wide approach that seeks to overcome many of the key methodological and epistemological challenges faced by existing agri-food research. ${ }^{1}$ In doing

\footnotetext{
${ }^{1}$ Framing our argument in terms of the 'agri-food' system should not be taken to imply an undue emphasis on terrestrial cropping systems. We also acknowledge the importance of livestock farming and fisheries, using 'agri-food' as a short-hand for the broader food system.
}

so, this paper also locates a number of initial successes in implementing this approach as well as offering insights about how a system-wide agenda could be moved forward.

A system-wide approach to agri-food research enables questions of the following type to be answered: what might be the effect of a change in a particular consumer habit on crop production, resource use, nutrition and health? What would be the implications for the food producer, retailer and consumer of a change to more sustainable and resilient crop production, through a new plant variety or agronomic practice? What are the implications for the food security of farmers in poorer countries of changes to markets, consumption and trade across global production networks and value chains? How can changes to land tenure, input pricing, credit, financing and sales improve the food security of the poorest farmers internationally? How can food waste be reduced to ensure the most efficient functioning of the agri-food system? Where are the pressure points or sites of greatest sensitivity to change? Where are the 'hotspots' in terms of resource use, environmental effects or waste? How do we adapt agri-food systems to climate change? How do we present the different solutions required for each of the huge diversity of crops and locations, or types and sizes of farms? Which solutions and trade-offs are most effective, practical and acceptable, and what can be done to foresee the unintended consequences of proposed interventions?

\section{Developing an agenda for agri-food research}

Developing a more interdisciplinary and system-wide approach would involve five steps: 1 , describing the agri-food ecosystem; 2, identifying the research themes that emerge; 3 , defining a quantitative methodology for analysing and modelling agri-food ecosystems and thereby integrating these research themes; 4 , establishing a complementary methodology to address the political, ethical and legal tensions within the ecosystem; and 5, setting out an agenda for agri-food research that exploits the ecosystem concept to develop innovative ways to combine these two approaches into an analytical framework for determining, evaluating and implementing new agri-food policies and technologies. The remainder of this paper outlines this approach in more detail, discussing how it can meet the challenges of interdisciplinary research and how working across disciplinary domains can have a transformative effect on each research area.

\section{Describing the agri-food ecosystem}

The first step in developing a system-wide approach to agrifood research is to describe what the system is, what processes to include and where to set boundaries. From first principles, the agri-food system comprises all of the processes involved 
in producing and consuming food from the capture of sunlight by photosynthesis in plants, harnessing the ecosystem services provided by the agricultural landscape that are central to food production, through the conversion of plants and animal feed into human food, to the purchase, preparation, consumption and metabolism of foodstuffs by humans. Our increasingly globalized agri-food system is characterised by a growing separation between production and consumption with a range of corporations and institutions playing increasingly important intermediary roles.

Previous attempts to describe the complete system of agricultural production have included the idea of the 'agro-ecosystem' (Conway 1987). Under this model, after establishing a suitable ecosystem boundary, all of the processes and participants in crop production were defined, allowing material flows, interactions, inputs and outputs to be described and analysed. This model was found to be suitable for describing the whole agri-food system and in previous work we expanded the range of processes and stakeholders to create an agrifood ecosystem (Horton et al. 2016). The agri-food ecosystem model was used to create an analytical framework for improving resource efficiency and sustainability in food supply chains. This model went through a large number of modifications arising from its exposure to multidisciplinary experts including university academics and leaders from research funding bodies and industry. The updated model is outlined in Fig. 1: Fig. 1a shows the actors involved, the external influences, and more detail of the inputs and outputs involved in food production and consumption; and Fig. 1b shows the sources of loss and waste, the environmental and health penalties than can ensue and the environmental and socioeconomic benefits of the agri-food system. The unifying definition of waste across the entire system should be noted in Fig. 1a, which includes inefficiencies at the farm level as well excess eating as a part of such waste (Horton et al. 2016). The contemporary agri-food system is subject to many external influences including the actions of NGOs and pressure groups, innovations in science and technology, labour unrest and geopolitical events, together with natural hazards such as flooding and drought, which can have a significant impact on the resilience of agri-food systems as was demonstrated by the 2007-8 'price shock' (Mittal 2009).

This conceptualization of the agri-food system seeks to integrate: agricultural and land-use strategy; crop production and harvesting; corporate and farmers' means for managing labour, credit, technology and sales; food processing, storage and distribution; retailing; and purchasing, preparation and consumption. It demonstrates how losses and waste occur at all points in the system, illustrating the environmental impacts of food production and consumption and highlighting the human consequences of the agri-food system in terms of the health-related outcomes of dietary decisions (often highly constrained by socio-economic circumstances). The model is presented in linear terms but, in practice, agri-food systems are usually complex networks including significant feedbacks and interactions (as outlined by Ericksen (2008) in her work on conceptualizing food systems). Figure 1a highlights interactions between the various actors (by horizontal filled arrows), recognising the importance of consumers in influencing the provision of food and the various external factors (indicated by dotted arrows). Figure $1 \mathrm{~b}$ includes the important feedback from environmental impacts, which can lead to further losses in crop yield, increase in food waste and amplification of health effects (dotted arrows). We also show that the agrifood system has numerous other outputs besides food for human consumption, including food waste, animal waste, nonfood biomass and human sewage. The importance of representing them in this way is that they can be viewed as a resource which can be utilised and even fed back into the system (dotted arrows). Thus, waste can be converted to energy via anaerobic digestion or processed to recover valuable resources, such as fertiliser (Li et al. 2015).

The ecosystem model in Fig. 1 is generic - it can be used to describe any agri-food system, in any part of the world. Clearly, different processes would be more important in different cases. For example, yield losses are more significant in harsher climatic conditions or in nutrient-poor soils and postharvest losses rise in low and middle-income countries because of inadequate storage and inefficient transportation networks, whereas food waste at the consumer level is endemic in high income countries. ${ }^{2}$ Structures may also differ in terms of the scale of farms, agronomic practices, the nature of the food industry and so on. But in every case, system-wide perspectives can be formulated following the principles of this model.

\section{Identification of research themes}

New programmes of agri-food research and development have been identified through the adoption of this kind of ecosystem thinking. Examples include the RCUK and N8 agrifood resilience programmes. ${ }^{3}$ Our formulation identifies five inter-connected research domains: Land Use and Resource Management; Crop Production and Harvesting; Food

\footnotetext{
$\overline{2}$ Throughout the paper we employ the World Bank's definition of high, middle and low-income countries, sometimes referred to as HICs, MICs and LICs (see http://data.worldbank.org/about/country-and-lending-groups, accessed 9 December 2016).

${ }^{3}$ In collaboration with Defra, FSA and the Scottish government, BBSRC, ESRC and NERC have allocated $£ 14 \mathrm{~m}$ for research on the resilience of the UK food system in a global context (http://www.bbsrc.ac.uk/funding/filter/food-system-resilience/, accessed 9 December 2016). The N8 agri-food programme has a $£ 8 \mathrm{~m}$ budget from the HEFCE Catalyst fund (with matched funding from the eight partner universities), organised in three research strands on sustainable food production, resilient supply chains and improved consumption and health (http://n8agrifood.ac.uk/, accessed 9 December 2016).
} 


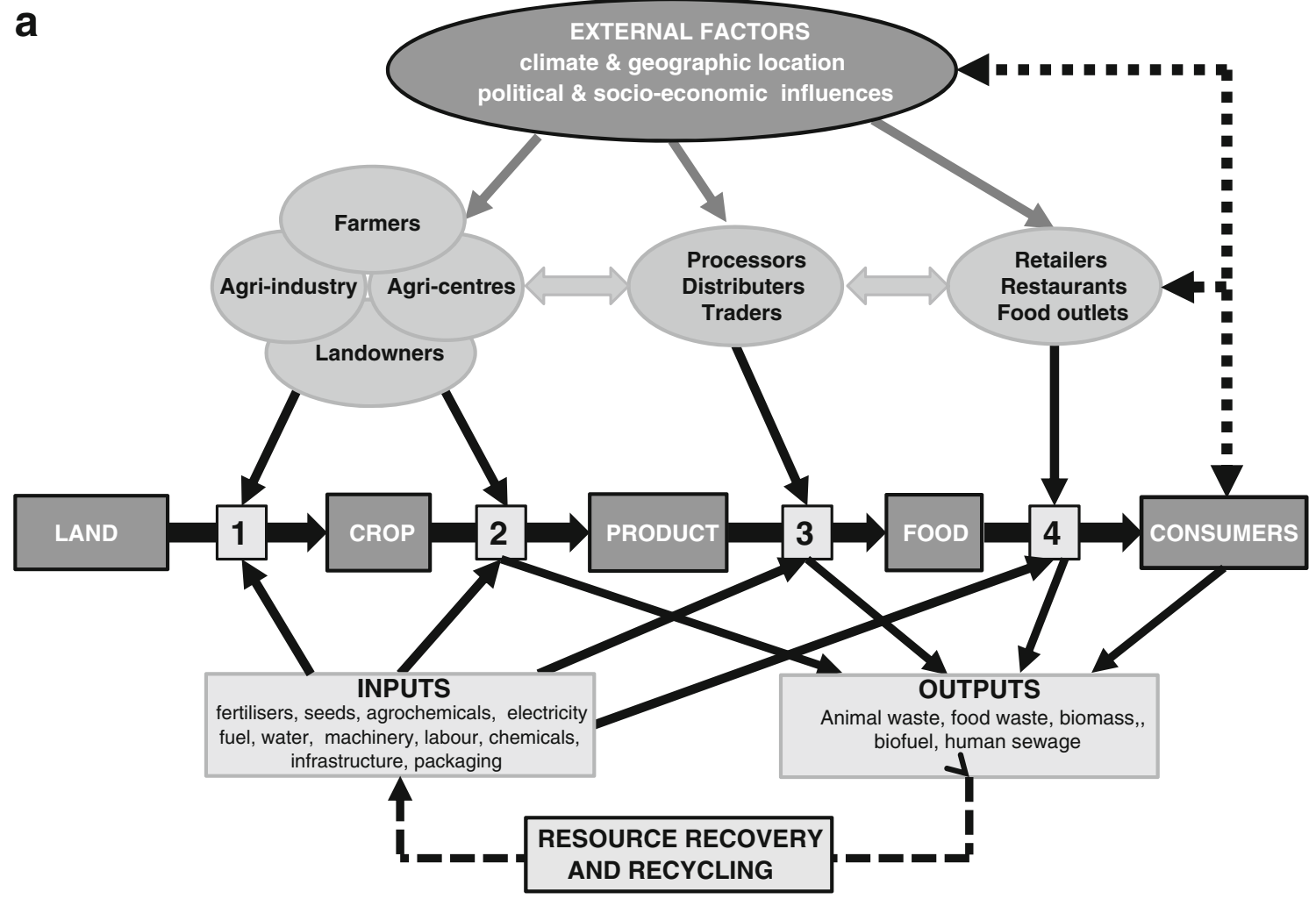

b

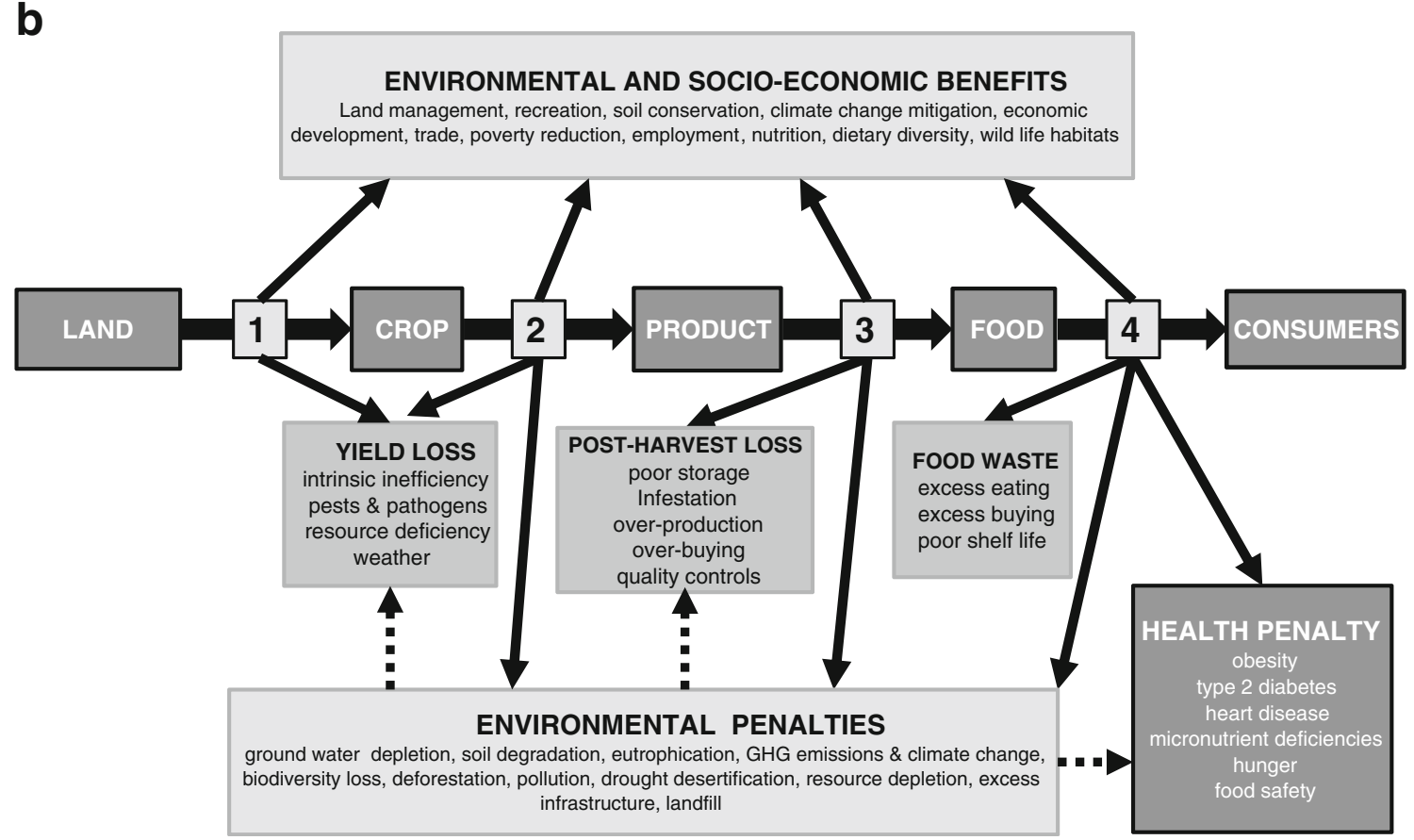

Fig. 1 Diagramatic representation of the agri-food ecosystem (a). The agri-food ecosystem consists of four processes: 1. Agricultural and Land use strategy, 2. Crop production and harvesting; 3. Processing, storage and distribution; 4. Retailing and consumption. These are controlled by various interacting stakeholders. Inputs and outputs are described, including resource recovery and recycling. The whole system is under the influence of a range of external factors. Consumers feedback through their influence on stakeholder behaviour and the external socio-political factors. b The impacts of the agri-food ecosystem, the environmental and health penalties, and the various benefits emanating. Shown are the losses that occur at each process stage, with the concept of physiological inefficiency, yield gaps, post-harvest loss, food waste and excess consumption all considered under a general heading of "waste". Note the important feedback of environmental impact upon all stages of the agri-food system, increasing both the waste and the ill-health impacts 
Processing, Distribution and Sales; Food Consumption; and Nutrition and Public Health (Fig. 2). Clearly there are overlaps and synergies among these five domains in that they combine to address the three fundamental aspects of food security i.e. Farming and Agri-technology; Food Business and Retailing; and Food Choice, Diet and Health. A range of research questions have been identified in each of these five domains and it is clear that, due to the highly interconnected food supply system, the answers to many of these questions depend on understanding events and processes taking place in other domains. Asking questions within the framework proposed in Fig. 1 also has a transformative impact on the framing of questions within each domain as we now seek to illustrate.

In Land Use and Resource Management research a principal objective is to understand the pressure on global land and soil from the demographic drivers of increasing human population and wealth as well as related pressures on other resources such as water. Providing space for building puts pressure on the land available for agriculture, and both squeeze out land needed to maintain habitats and biodiversity (Blum 2006). Meeting the projected demand for food by 2050 is estimated to require an additional $320-850$ Mha of productive land (UNEP 2014). However, it is impossible to consider land use issues in the absence of knowledge arising from other research domains. Land area predictions are dependent upon future dietary patterns that become associated with high and middle-income country economies and some 540 Mha could be saved by 2050 through the global adoption of a vegetarian diet compared to the predicted global average diet associated with increasing prosperity (Tilman and Clark 2014). Furthermore, future crop yields, dependent in part on the introduction of new crop varieties and improved agronomic practices, determine how much more land will be needed, whilst the requirement to reduce greenhouse gas emissions from agriculture will inevitably restrict further marginal land transition (Godfray et al. 2010). Finally, future scenarios for climate change mitigation indicate the need for increased use of biofuel crops, creating potential tension in land allocation and threatening food production (Reilly et al. 2012; Searchinger et al. 2015; Phalan et al. 2016). All of this indicates the need for detailed, high resolution data on global land use patterns and change: linked monitoring, mathematical modelling and forecasting of the integrated environment and agriculture production system (Banwart et al. 2013). The capability of geospatial ground-based and remote sensing of environmental conditions in real-time then links dynamically to computational simulation of environmental processes for forecasting of ecosystem functions and services. This methodology will deliver the capability to design and operate land management for food production.

Demand for land is additionally complicated by the fact that intensive agriculture is putting enormous pressure on soils (Banwart 2011). In the past quarter of a century, around 25\% of the Earth's productive land has been degraded, primarily through the loss of soil organic matter (Bai et al. 2008; Montgomery 2007) and accompanying depletion of soil fungi and bacteria (Helgason et al. 1998; Cameron 2010). The rate of soil degradation is highly dependent not just upon agricultural practice but upon the frequency of extreme climatic events. Therefore, research is being directed to understand how to prevent further soil loss by rebuilding communities of beneficial soil microbes in agricultural soils and encouraging the adoption of novel agricultural management strategies that restore soil ecosystem function (Cameron et al. 2013). An important element of this research is the collaboration between scientists and farmers, deploying scientific knowledge about soil conservation in farming practices (MacMillan and Benton 2014).

In poorer parts of the world, food security of small-scale farmers reflects not just lack of land, but lack of access to credit, farm inputs such as fertilisers and adequate labour. These can be intensified by their occurrence at key times of the year in crop production cycles. Therefore research needs to explore how small-scale farmers manage labour, credit and
Fig. 2 A programme for integrated agri-food research, showing the five core areas of investigation (dark grey), which together address the issues of farming and agri-technology, food business and retailing, and food choice, diet and health (white). Two overarching research activities span the core areas (light grey). For further details refer to the text

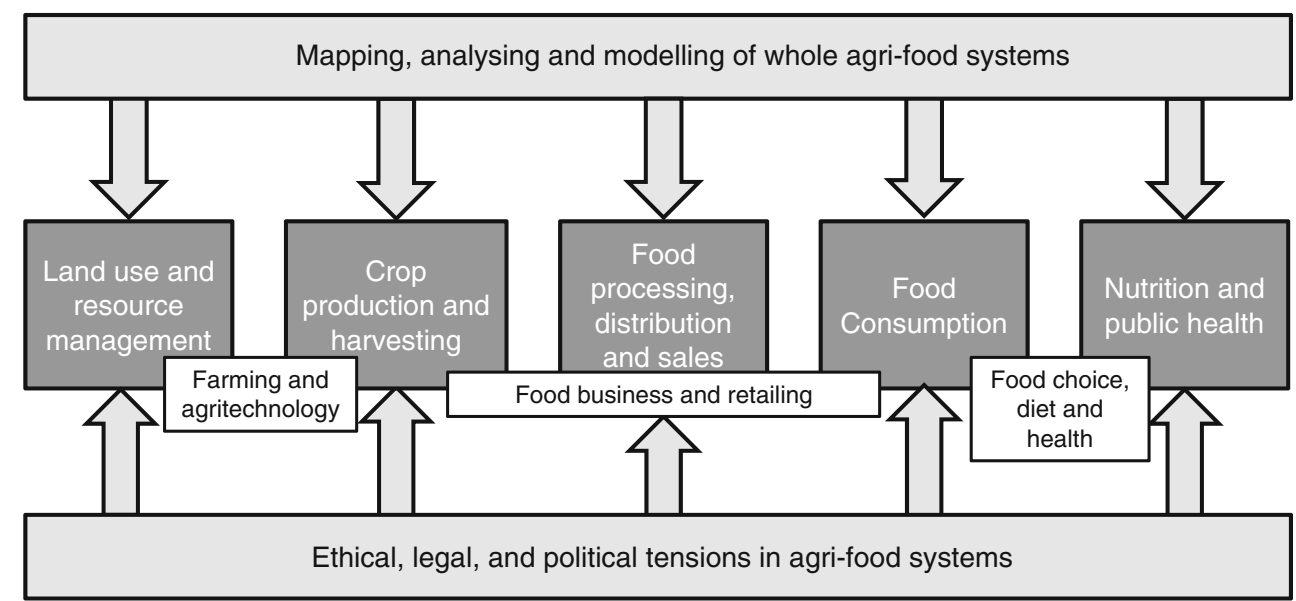


social networks to improve farm productivity, as well as examining how they combine agricultural livelihoods with nonagricultural work to improve food security (Arndt et al. 2016)

Research in Crop Production and Harvesting has traditionally been confined to the study of the physiology and genetics of crop plants, establishing new crop varieties, discovering new agrichemicals and devising improved agronomic methods. There is a continued need for such research, and there are global initiatives aimed at delivering increases in yield potential of the major cereal crops (Murchie et al. 2009; Furbank et al. 2015). Similarly, reducing the yield gap is an active research target since many crop yields have reached a plateau or are even decreasing (Foley et al. 2011). Increasingly, however, agricultural research is driven by wider concerns, such as: predicted yield reductions through the effects of climate change and severe weather events (Lesk et al. 2016); greenhouse gas emissions associated with the manufacture of nitrogen-based fertilisers and pollution of water courses through run-off (Zhang et al. 2015; Goucher et al. 2017); and external economic and geopolitical events in connection with another constituent of fertiliser, phosphorus, because it is a finite global resource (Dawson and Hilton 2011; Syers et al. 2011). Thus, increasing the availability of nitrogen and phosphorus to plant roots via soil microbe activity has emerged as another research target (Cameron 2010). Similarly, research on pests and diseases, a second major factor in the yield gap, is assuming new urgency as a result of many external factors, including resistance to agrochemicals, the effects of climate change and efforts to conserve biodiversity (Lamberth et al. 2013). Like many effects of climate change it is thought that LMICs will be most affected. For example, research has focussed on combatting one of the major threats to rice production in Africa, infestation by the parasitic weed Striga spp. (Rodenburg et al. 2015). Because of concerns over soil degradation discussed above, any improvements in yield have to take place through conservation agricultural practices, such as no tilling and other measures such as retention of crop residues and crop rotation (Pittelkow et al. 2015). To help meet all these agricultural challenges requires that new discoveries in plant science are efficiently and quickly translated into application. Moreover, it requires that the end-users - farmers and agribusiness - work closely with plant scientists during project development, equivalent to that occurring in translational medicine (Woolf 2008), so that new discoveries are properly integrated with complementary improvements in agronomic practices.

Many of the required improvements in crop plants can be brought about through genetic manipulation, particularly significant where conventional breeding techniques cannot be used to introduce the desired traits (Davies et al. 2009). However, the use of GM crops remains controversial (Jacobsen et al. 2013), and collaborations between scientists and social scientists are crucial to understand the reasons underlying the hostility towards this technology in some sections of the public. This becomes even more relevant in the light of the latest advances in gene editing technology, such as CRISPR-Cas9, which are conceptually different from conventional GM techniques (Song et al. 2016). Hence, introducing new agri-technologies is not straightforward even if scientific and technical barriers can be overcome. As will be discussed further, the issue of GM foods exemplifies the fact that social, political and ethical considerations have to be taken into account, where the methods outlined in "An agenda for agri-food research: research gaps and future challeges" section may be useful. Failing to address these issues can lead to inefficient translation of new technologies that have high potential to increase sustainability and efficiency of crop production. There is consequently a requirement for integrated research approaches in which all the repercussions of new agritechnologies are considered including discovering the changes in cost, resource use, suitability for storage or processing, appearance, taste and nutritional value of the products of new crops, as well as public perception of benefits and risks.

Informed by an integrated agri-food perspective, research on Food Processing, Distribution and Sales has two aspects. In wealthier countries, the effects of retail concentration and the increasing complexity of food businesses and their lengthening supply chains are key priorities. In poorer countries many of these also apply, but, in addition, researchers are concerned with how farmers collaborate and work collectively to improve returns from their activity and access credit and important inputs. In the global North this matters because food retailing is highly concentrated, dominated in many countries by a small number of companies who exert very strong power over their suppliers, often driving down prices (Free 2008). Lower profit margins and higher volumes from a more limited supplier base encourage the drive to lower prices and increased sales, creating a vicious circle of dependency. Conversely, in the global South, access to higher value export and urban markets can depend on the ability to aggregate crops from large numbers of smaller-scale farmers. Thus, food business cannot be disentangled from farming and agriculture. Research also needs to address the growing disconnection between the points of production and consumption which has been held responsible for consumer detachment from where food originates, how to prepare it safely and how to avoid waste (Cook et al. 1998). ${ }^{4}$ The 2013 horsemeat incident, ${ }^{5}$ which became a highly publicised news story revealing perceived failures in the food

\footnotetext{
${ }^{4}$ The Food Standards Agency's recent summit on Our Food Future (February 2016) highlighted a link between convenience and connection where it was argued that an increasing reliance on processed food led to a growing sense of disconnection between food producers and consumers (https://www.food.gov. uk/sites/default/files/our-food-future-full-report.pdf, 9 December 2016).

${ }^{5}$ The discovery of horsemeat in processed beef products sold by a number of UK supermarket firms drew media attention to the length and complexity of food supply chains (http://www.bbc.co.uk/news/uk-21335872, accessed 9 December 2016).
} 
supply system, also highlighted the potential costs of lengthy and complex supply chains in terms of a lack of transparency and potential loss of consumer trust (Premanandh 2013). Legislation and official guidance, often regarded as undue interference by retailers and suppliers, has been used to promote healthy eating, but may lead to further uncertainty and anxiety as can arise from consumer confusion over the proliferation of product labelling and expiry dates (Milne 2012). This further emphasises the need to take a whole systems approach when predicting the likely impact of food policy changes.

An integrated approach to agri-food systems demonstrates how research on Food Consumption should seek to connect the behaviour of consumers, as individuals and groups, to the systems of provision that make food available to them and to explore the consequences of their (often highly constrained) food choices in terms of social, environmental and health effects.Food is also fundamental to people's sense of identity, intimately linked to notions of gender, class and ethnicity and important in symbolic as well as material terms (Probyn 2000). Current trends in food consumption in the global North are unsustainable whether measured in terms of public health, environmental impacts or socio-economic costs (Moomaw et al. 2012) and there are clear links between socio-economic status, dietary intake and health outcomes at every geographical scale (discussed in the following section). The conventional approach to the challenges of 'over-consumption' in HICs has been to advocate a range of behaviour change initiatives, based on the assumption that increased consumer knowledge will lead to desirable changes in attitudes and behaviour. ${ }^{6}$ But, as the Foresight report on 'Tackling Obesity' recognised, 'policies aimed solely at individuals will be inadequate', emphasising the need for 'wider cultural changes' involving coordinated action by government, industry, communities, family and society as a whole (OST 2007). Acknowledging the socially embedded character of much consumer behaviour (Murcott 1998; Jackson 2009), with many dietary decisions being habitual in nature, research is increasingly exploring the routinized character of consumer practice and the institutions and infrastructures that underpin it (Warde 2005; Delormier et al. 2009). As Evans' (2014) work on domestic food waste demonstrates, food is deeply implicated in our everyday lives and household food practices are highly conventional in character, reproduced through domestic routines, institutional systems and enabling infrastructure. Initiatives that are designed to promote healthier and more sustainable modes of consumption need to address the socio-technical systems that enable and constrain them rather than focusing exclusively at the individual level (cf. Shove et al. 2012). ${ }^{7}$ Consumers' changing tastes and preferences also

\footnotetext{
${ }^{6}$ For a critique of this approach to behaviour change, see Shove (2010).

${ }^{7}$ Public procurement of food for hospitals, schools and other institutions may also offer significant potential for encouraging dietary change with benefits for health and sustainability (cf. Sonnino 2009).
}

shape other parts of the food system (as discussed below in terms of the health consequences of dietary change). Finally, consumer research illustrates how diet-related decisions raise a host of ethical challenges and complex trade-offs which may seem insuperable in principle but which are "negotiated into practice' by consumers on a daily basis (Watson and Meah 2013). So, for example, consumer preference for organic food (on health or sustainability grounds) may be traded off against a desire for local food (produced via intensive farming methods but with fewer 'food miles') - or the immediate demand to feed one's family in the most economical way may trump more abstract ethical commitments to 'distant strangers' in far-off producer countries (Jackson et al. 2009).

Nutrition and Public Health research is traditionally studied in isolation from the rest of the agri-food system. However, more recently the inter-relationships between nutrition and food production have been investigated, particularly in the context of climate change, growing populations and urbanisation. For example, the SUNRAY study in Africa (Lachat et al. 2014; Tirado et al. 2012) has highlighted the importance of prioritising research into what works to prevent malnutrition (in all its forms) by evaluating community nutrition interventions. The public health landscape is likely to become even more complex as countries, especially LICs, face environmental threats from climate change, food scarcity and water shortages, as well as socio-demographic and related dietary changes, where increasing wealth is leading to widespread dietary change, making interdisciplinary working increasingly important (Holdsworth et al. 2014). The research agenda needs to reflect this, broadening to include the impact of diet on the natural environment as well as the impact of environmental change on all components of food security (Tilman and Clark 2014).

An integrated approach to agri-food research also draws attention to the impact of social and political conflicts on health and malnutrition. Environmental change can exacerbate under-nutrition by limiting the capacity to grow food. Extreme weather events (such as droughts and flooding) can contribute to volatile food prices (Godfray et al. 2010) leading, in some cases, to food riots, civil unrest and increased hunger. When food and water become scarce there is increased chance of war and conflict (UNEP 2007), while the FAO acknowledge that armed conflict is one of the main causes of hunger in LMICs. These compound factors pose multifaceted public health and nutrition challenges which can only be addressed by interdisciplinary research in which all of the components depicted in Fig. 1 are simultaneously considered.

Integrated agri-food research also faces the challenge of feeding the 805 million people suffering from hunger (FAO 2014) and the 2 billion people suffering with a micronutrient deficiency (including iron, vitamin A and zinc), mainly as a consequence of a monotonous diet (Webster-Gandy et al. 2012; WHO 2001). A second public health challenge is diet- 
related non-communicable disease - a major problem in HICs but now increasing in LMICs (Ebrahim et al. 2013), particularly in urban areas due to changing dietary habits and sedentary lifestyles (Delpeuch et al. 2009). The 'nutrition transition' also poses significant public health challenges, signalling a shift in the structure of the diet towards more energy-dense foods, a higher consumption of ultra-processed convenience foods and animal protein, a lower intake of high-fibre starches, fruit and vegetables, and an increase in the total quantity of food eaten (Popkin et al. 2012). This diet is more carbonintensive and obesity-promoting (Stern 2006; Tilman and Clark 2014), raising concerns about the health and sustainability challenges of an increasing reliance on 'convenience' food (Jackson and Viehoff 2016). Serious concerns have also been voiced about the impacts of a worldwide growth in meat consumption not only on health but also on the sustainability of the global agri-food system (McMichael et al. 2007; Holdsworth et al. 2014; Clonan et al. 2016), because meatbased diets use more water, primary energy, fertilizer and pesticides (Marlow et al. 2009), generating more greenhouse gas emissions than plant-based diets. Hence, research needs to focus on both under- and over-nutrition, including the interrelationships between them, acknowledging the social and physical environments that drive people's dietary habits.

\section{Quantitative analysis and modelling of agri-food ecosystems}

The above discussion clearly shows that sustainable food security solutions will depend upon knowledge that drives a step-change in innovation, which spreads throughout agrifood systems. To achieve this goal requires a systems approach, designed to quantify and integrate all of the relevant processes and components involved (Hammond and Dube 2012; IOM and NRC 2015), increasing the visibility of the upstream and downstream processes shown in Fig. 1. Globalscale models of the agri-food system have been proposed (Foley et al. 2011) and these have contributed to the development of national and global agri-food policy. However, a methodology that can be routinely applied to specific agrifood systems is also needed. Such methodology would not only enable analysis of their efficiency and sustainability but also, most importantly, prediction of the effects of specific interventions and changes.

One way forward involves the development and application of the method of Life Cycle Assessment (LCA). LCA is used extensively in industry to identify 'hotspots' in greenhouse gas emissions (O'Rourke 2014; Hellweg and Canals 2014) and has been applied to food supply chains (Garnett 2014; Goucher et al. 2017). An example of such methodology is the Supply Chain Environmental Analysis Tool (SCEnAT), a robust supply chain life-cycle analytical modelling tool which integrates Traditional LCA and Environmental Input-
Output LCA, quantifying the environmental impact of human-led activities (Guinee and Heijungs 2011; Koh et al. 2012; Horton et al. 2016). Environmental Input-Output LCA offers the advantage of an extended system boundary, equivalent to the agri-food ecosystem concept in Fig. 1, in which all the inputs and environmental impacts can be estimated. The notion of an integrated process is central, based upon the mapping of whole agri-food systems, their quantitative analysis based on enhanced LCA, the use of emergent data to catalyse viable and commercially attractive innovation and the free access of data to all stakeholders and, in particular, consumers as the principal engine for change (Horton et al. 2016).

This approach will only succeed if there are equally high levels of input from all the parts of the agri-food system denoted in Fig. 1. Detailed agricultural models have to be combined with equally detailed supply chain models, together with quantitative representations of food consumption and nutrition. This requires collaborative research across the five research domains described in Fig. 2. There are many challenges including: setting system boundaries in terms of what to include and exclude; identifying and gaining access to robust sources of data from primary suppliers (farmers and agrifood businesses); and seeking acceptable proxies for inputs where quantitative data are unavailable. Research is needed to develop and refine these tools, to allow incorporation of a range of environmental impact indicators and to quantify the demand side of the supply chain. Combining the insights of qualitative research, often at the micro-scale, in ways that are compatible with the epistemological and methodological assumptions of macro-scale models also needs to be recognised and addressed. Thus, can we: analyse patterns of human behaviour, such as those that determine food preferences; measure the health penalties and benefits in a way that is useful in terms of supply chain analysis; quantify environmental impacts across the food chain in a unified and robust way that allows monetization? Recent work elsewhere gives cause for optimism including: quantitative analysis of ecological functions (ecosystem services) through monetization (Bateman et al. 2013); developing integrated environmental impact indices (O'Rourke 2014); and defining agricultural yields in terms of people nourished per hectare (Cassidy et al. 2013).

\section{Ethical, legal, and political tensions in agri-food ecosystems}

In order to achieve a truly integrated analysis of agri-food systems, a method of quantitative analysis and a modelling tool as described in the previous section is necessary but insufficient. Understanding the ethical, legal and political issues that shape agri-food systems is also required. Integrating insights from the political and social sciences into agri-food research is crucial because food security will require more than the examination of food production and consumption from a purely scientific or 
technological point of view. This is because questions regarding the distribution of the 'goods' associated with food systems involve inherently political decisions necessitating research on complex decision-making processes. Understanding the inherently political dimensions of the agri-food system is also required because various aspects associated with food security, including the inconsistencies of national and supra-national policy-making over issues such as dietary guidelines and food subsidies, are potentially in tension, demanding practical as well as ethical trade-offs due to limited resources and unequal access to them (Gottwald et al. 2010; Zollitsch et al. 2007; Lang and Heasman 2004). Good examples of such tension are use of corn (maize) as a biofuel feedstock, driven by government incentives, which reduces that available for food, with the potential to drive up prices (Tenenbaum 2008) and the clearing of tropical rainforests for oil-palm, which resulted in health risks from the fire-related air pollution that has ensued (Sukhdev et al. 2016). Acknowledging these challenges, a methodology is required for examining how different interest groups negotiate and ethically balance the use of resources including how they are distributed, consumed and sustained for future generations. The development of such a method is outlined in "An agenda for agri-food research: research gaps and future challenges" section.

An integrated approach to agri-food research is ultimately concerned with justice, since theories of social justice offer us first principles by which to determine 'who gets what and why" in any socio-economic or political system (Allen 2008; Clapp 2012). Research on global food security must also address larger ethical and practical questions about substantive and procedural justice (both domestically and globally) and a resulting just distribution of food system-related benefits and burdens.

As Fig. 1 illustrates, every level of the agri-food system is subject to political influence. This is true in terms of agricultural regulation, public health policy, environmental standards, food waste programmes and policy incentives. It also applies to the political-economic dimensions of food security including the capitalist structures that govern global food production and distribution (Morgan et al. 2006). Decisions about how to respond to food security concerns will have considerable moral/ethical implications. Such ethical considerations must be taken into account within any heuristically viable approach to agri-food research. Long-term, politically legitimate solutions will necessarily involve better understandings of existing food-related political structures, processes and alternatives.

\section{An agenda for agri-food research: research gaps and future challenges}

In sections "Describing the agri-food ecosystem" and "Identification of research themes" we have described the complex nature of the challenges and research questions that are contained in the agri-food ecosystem. We have shown how finding solutions within each of the research domains that emerge from this ecosystem view is highly dependent upon understanding processes occurring elsewhere in the system, as well as on a host of external factors. "Quantitative analysis and modelling of agri-food ecosystems" section demonstrated that a systems-wide approach provides a quantitative methodology for discovering the most effective and efficient interventions. "Ethical, legal, and political tensions in agri-food ecosystems" section then established that understanding how to devise and deliver sustainable agri-food systems is wholly dependent on resolving the competing political and ethical influences upon it. In this section we ask whether these latter two research approaches can be brought together to provide a means for more fully integrated agri-food research.

One potentially viable method is to examine the socio-economic, political and ethical factors at each nodal interface along the food supply chain (Helmsing and Vellema 2011). In doing so, political science can offer established methods for performing stakeholder analysis, mapping existing 'regime complexes' and generating 'ethical audits' related to the various tensions among and between the parts of the agri-food ecosystem. The conceptual similarities between this approach and LCA are obvious - only the outputs differ. By locating these nodes (conceptually equivalent to 'hotspots' in LCA terminology) and through the use of innovative techniques for collective decision-making (such as deliberative fora), political scientists can offer viable methods for bringing stakeholders together to discuss, debate and communicate current tensions, with the aim of generating legitimate solutions that can be viewed as 'just', or at least 'more just' than present systems. These sorts of methods are not only heuristically valuable in terms of research impact, but are more legitimate, since studies suggest that trade-offs and radical policy solutions will be considered more legitimate when those affected were deliberators within decision-making processes and when procedures for reaching a final decision were open, clear and based on reliable information flows (Habermas 1998).

We propose that this analytical approach should be combined with the systems analysis approach that incorporates environmental and social impacts, exemplified currently by LCA, monetization of ecosystem services and other quantitative methods (Fig. 3). This dual approach could be employed to research a potential new agri-technology or to determine the likely effectiveness of a new policy or regulatory regime on the health and environmental sustainability of diets. An iterative multistep process of description, analysis and reflection would take place, expanding and formalising this theoretical approach (Horton et al. 2016). First, the new technology or policy would be formulated within the whole agri-food ecosystem context, mapping its components, processes and boundaries (as outlined above). It would then be subject to LCA. The data and evidence emerging from this analysis would be made available to all stakeholders for further analysis. This would involve two further stages of analysis: 


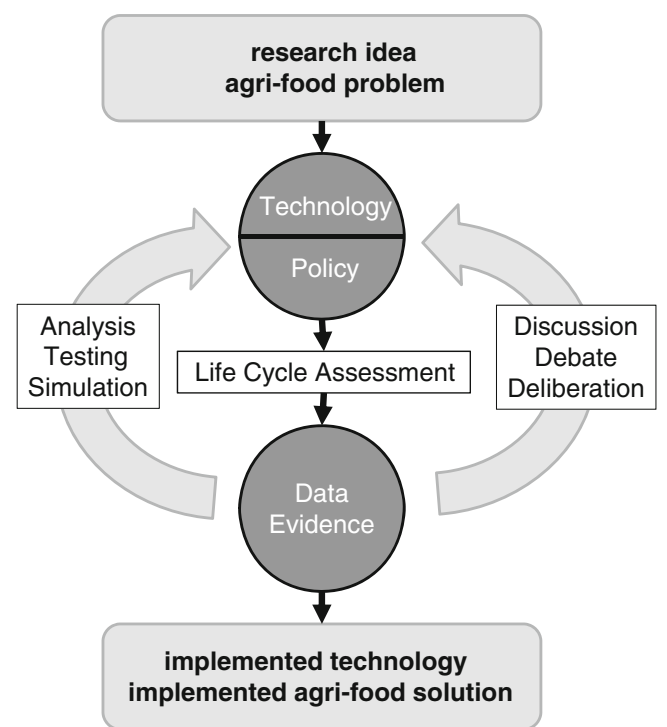

Fig. 3 A schematic representation of how the proposed research agenda would work to develop a new agri-technology or agri-food policy. LCA first produces evidence and data, which then stimulates further testing and modelling, discussion, debate and deliberation that together inform refinement of the technology or policy. For further details refer to the text

simulation modelling and experimental testing to fine tune the technology or policy; and debate and discussion, through deliberative fora and public engagement.

As suggested above, a promising mechanism for generating reflection and consensus among stakeholders in cases of evidence complexity and entrenched interests is through targeted 'deliberative fora', where multisectoral stakeholders and representatives within the agri-food system can be guided through a series of policy options and solutions. Through the use of deliberative methodologies, stakeholders would be steered to 'reason give', explain positions, present and reflect upon evidence (subjective and objective - with fact checking), and asked to offer their own insights for creating fair policy solutions in the light of existing competing positions and LCA findings. The key to deliberative fora therefore is to task stakeholders to better rationalise their positions so as to allow opportunities for constructive agreement toward an 'all points considered' or 'more points considered' policy solution. Although still experimental, deliberative fora have generated successful results in research trials in Canada, Australia and the United States, covering empirically complex and interestentrenched areas such as environmental policy, welfare allocation, health care and public infrastructure spending (Dryzek 2015). In this way, integration of these methods would inform modifications to the technology or policy. The revised technology or policy would then enter further cycles until it is shown to be competent to deliver key objectives. Consequently, a more integrated agri-food research methodology that adopts a system-wide approach and takes the role of politics seriously would not only assist the mapping out of existing bottlenecks involved in reforming agri-food systems, but would also offer innovative methods to effect the type of deliberative political change necessary to implement agri-food advances by securing 'buy-in'.

Of course there are significant barriers to the implementation of such methodologies, both singly and even more so in combination. The supply chains for the production and consumption of most food products are long, complex and inherently fragmented. Beyond the layer of primary suppliers, they are often unknown even to the businesses involved (O'Rourke 2014). Farmers grow crops, the food industry processes and distributes the produce, retailers sell and consumers purchase and eat the food. These actors are not integrated in their decision-making. Cross-sector relationships between these sectors are usually driven by economics alone and can exacerbate adverse environmental and health impacts, for example by promoting increased use of some resources and agrochemicals, increased waste and excessive consumption of unhealthy foods. Furthermore, having identified a system-wide solution to a problem does not resolve the question of where responsibility lies for implementing it. According to the principles of extended producer responsibility, all the actors in the supply chain should share responsibility (Lenzen et al. 2007). But several questons remain. Is our approach feasible within the structure of the agrifood system? Can all the actors necessary for an effective deliberative forum be brought together? Will all the data needed to provide evidence of the required precision, uniformity and transparency be forthcoming? Such obstacles need to be overcome if the potential benefits of system-wide agri-food research are to be realised. Taking the example of GM discussed above, the processes of scientific analysis and testing have previously often been divorced from the public discourse about risk and ethics. If the two processes were brought together as represented in Fig. 3, the conflict might be resolved - or at least the competing interests would be rendered more transparent such that trust between science, technology, government and public might be restored.

A second key barrier is the major conflict embedded in the agri-food system. The primary purpose of the food producing sectors is to make money not to provide sustainable global food security, the definition of which includes access to nutritious food (Trudge 2016). For example, high agricultural productivity, necessary for farmers, agri-businesses and food retailers to make a profit, whilst also keeping prices low for consumers, currently requires environmentally unsustainable farming practices. The drive to increase yields of corn and sugar cane leads to increased use of sweeteners, with consequent health effects. The environmental and health impacts of these practices are not costed within the system and thus, there are currently no effective incentives to implement the required improvement. For the reasons given above, regulations are often ineffective and have unforeseen consequences. Thus, even if rational, evidence-based solutions could be generated from the research approaches we are advocating, would they be implemented? 
Research is therefore urgently needed to find ways to incentivise all sectors of the agri-food system towards delivering food security (Haddad et al. 2016). This could include the following: refocusing agriculture upon nutrition by redirecting agricultural research away from a small number of cereals towards crops with higher nutritional value, such as pulses, vegetables and fruits; redefining agricultural metrics (Sukhdev et al. 2016), for example in terms of people nourished per hectare rather than yield (Cassidy et al. 2013); increasing the demand for production of healthy food by encouraging change in consumer practice; devising practical ways to incorporate externalities into the cost of food to take into account environmental impact; and extending our understanding of the link between diet and environment (Tilman and Clark 2014) with more high precision investigations of the environmental impact of particular food products, with sufficient granularity to reach firm conclusions and identify positive interventions (Horton et al. 2016; Goucher et al. 2017).

\section{Conclusion}

This paper has outlined the development of an integrated approach to agri-food research in order to address the complex challenge of food security. It has sought to map the agri-food system, to identify its component parts and to argue the case for approaching the system in an integrated way rather than as a series of separate domains. We have shown how taking this approach transforms the framing of research within each domain and we have proposed two ways of taking this agenda forward, through the application of quantitative analysis (using LCA and related methods) and through the recognition of the ethical, political and legal tensions that characterise the system (using deliberative fora). We have also identified some of the methodological and epistemological challenges of taking these ideas forward, acknowledging some of the barriers to their practical implementation.

Our approach might also be thought of in terms of the critical deployment of 'nexus thinking' (Leck et al. 2015), an approach that is being advocated in the UK through parallel research programmes from the ESRC and EPSRC and in a range of international initiatives. ${ }^{8}$ Rather than seeing energy, food and water resources as separate systems, nexus thinking addresses the inter-dependencies, tensions and trade-offs between these different domains, similar to the approach taken in this paper,

\footnotetext{
${ }^{8}$ ESRC has invested $£ 1.8 \mathrm{~m}$ in its Nexus Network programme (http://www. thenexusnetwork.org/ ), while EPSRC has invested $£ 4.5 \mathrm{~m}$ on as similar programme, focused on safeguarding the UK's food, water and energy security (https://www.epsrc.ac.uk/newsevents/news/ukwaterenergyfood/). Similar programmes are being developed in the US by the National Science Foundation (https://www.nsf.gov/pubs/2016/nsf16524/nsf16524.htm). There is a Future Earth Network on the nexus (http://futureearth.org/future-earthwater-energy-food-nexus) and an urban-focused nexus call from the Belmont Forum (https://belmontforum.org/sustainable-urban-globalinitiative-sugi-food-water-energy-nexus, all accessed 9 December 2016).
}

moving beyond national, sectoral, policy and disciplinary silos to identify more efficient, equitable and sustainable ways of using scarce resources. While some have criticised the concept as little more than a contemporary 'buzzword' (Cairns and Krzywoszynska 2016) and others have promoted the value of nexus thinking in methodological terms (Stirling 2015), we are keen to put the concept to work through practical applications that explore the links between food, energy and water security at a range of geographical scales. ${ }^{9}$ Consistent with the idea of nexus thinking, this paper has sought to outline an integrated agenda for system-wide interdisciplinary agri-food research, capable of addressing the global challenges of enhanced food security.

Acknowledgements All the authors (except SAB) are part of the University of Sheffield Sustainable Food Futures (SheFF) research group or the P3 Centre of Excellence in Translational Plant Science, which both contribute to the Grantham Centre for Sustainable Futures. GWB acknowledges the intellectual contributions of Drs Hayley Stevenson and Alasdair Cochrane. The authors wish to thank all members of SheFF for advice and discussion. We acknowledge, in particular, valuable discussions with Professors Tim Benton (RCUK's global food security champion), James Wilsdon (Director of ESRC's Nexus Network) and Chris Tyas (Head of global supply chains at Nestlé).

Author contributions $\mathrm{PH}$ and PAJ devised, planned, edited and revised the paper. All authors wrote individual sections of the paper and assisted with the final revisions.

\section{Compliance with ethical standards}

Competing interests We have no competing interests.

Funding JT receives funding from an ERC consolidator grant (no. 309944 Prime-A-Plant) and a Research Leadership Award from the Leverhulme Trust (no. RL-2012-042). PAJ receives funding from the ERA-Net SUSFOOD programme (no. FO0459). RB is supported in part by the Grantham Foundation for the Protection of the Environment. SAB was supported by catalyst funding from The University of Sheffield Vice-Chancellor's Office.

Open Access This article is distributed under the terms of the Creative Commons Attribution 4.0 International License (http:// creativecommons.org/licenses/by/4.0/), which permits unrestricted use, distribution, and reproduction in any medium, provided you give appropriate credit to the original author(s) and the source, provide a link to the Creative Commons license, and indicate if changes were made.

\section{References}

Allen, P. (2008). Mining for justice in the food system: perceptions, practices and possibilities. Agriculture and Human Values, 25, 157-161. Arndt, C., McKay, A., \& Tarp, F. (Eds.). (2016). Growth and poverty in sub-Saharan Africa. Oxford, UK: Oxford University Press.

\footnotetext{
${ }^{9}$ This work has already begun through an ESRC-funded project on 'Reframing the domestic nexus' (https://nexusathome.wordpress.com/, accessed 9 December 2016) and it is the focus of a current bid to the Global Challenges Research Fund.
} 
Bai, Z. G., Dent, D. L., Olsson, L., \& Schaepman, M. E. (2008). Proxy global assessment of land degradation. Soil Use and Management, $24,223-234$

Banwart, S. (2011). Save our soils. Nature, 474, 151-152.

Banwart, S.A., Chorover, J., Gaillardet, J. et al. (2013) Sustaining Earth's critical zone - basic science and interdisciplinary solutions for global challenges. UK: The University of Sheffield ISBN.

Bateman, I. J., et al. (2013). Bringing ecosystem services into economic decision making: land use in the United Kingdom. Science, $341,45-50$.

Beddington, J. (2010). Food, energy, water and the climate: a perfect storm of global events? London: Government Office for Science.

Blum, W. E. H. (2006). Functions of soil for society and the environment. Reviews in Environmental Science and Biotechnology, 4, 75-79.

Cairns, R., \& Krzywoszynska, A. (2016). Anatomy of a buzzword: the emergence of 'the water-energy-food nexus' in UK natural resource debates. Environmental Science \& Policy, 64, 164-170.

Cameron, D. D. (2010). Arbuscular mycorrhizal fungi as (agro)ecosystem engineers. Plant and Soil, 333, 1-5.

Cameron, D. D., Neal, A. L., van Wees, S. C. M., \& Ton, J. (2013). Mycorrhiza-induced resistance: more than the sum of its parts? Trends in Plant Science, 18, 539-545.

Cash, D. W., Adger, W. N., Berkes, F., Garden, P., Lebel, L., Olsson, P., \& Young, O. (2006). Scale and cross-scale dynamics: governance and information in a multilevel world. Ecology and Society, 11(2), 8.

Cassidy, E. S., West, P. C., Gerber, J. S., \& Foley, J. A. (2013). Redefining agricultural yields: from tonnes to people nourished per hectare. Environmental Research Letters, 8, 034015.

Clapp, J. (2012). Food. Cambridge: Polity.

Clonan, A., Roberts, K. E., \& Holdsworth, M. (2016). Socioeconomic and demographic drivers of red and processed meat consumption: implications for health and environmental sustainability. Proceedings of the Nutrition Society, 29, 1-7.

Conway, G. (1987). The properties of agroecosystems. Agricultural Systems, 24, 95-117.

Cook, I., Crang, P., \& Thorpe, M. (1998). Biographies and geographies: consumer understandings of the origins of foods. British Food Journal, 100, 162-167.

Davies, B., Baulcombe, D., Crute, I., Dunwell, J., \& Gale, M. (2009). Reaping the benefits: science and the sustainable intensification of global agriculture. London: The Royal Society.

Dawson, C. J., \& Hilton, J. (2011). Fertilier availability in a resourcelimited world: production and recycling of nitrogen and phosphorus. Food Policy, 36, 14-22.

Delormier, T., Frohlich, K. L., \& Potvin, L. (2009). Food and eating as social practice: understanding eating patterns as social phenomena and implications for public health. Sociology of Health \& Illness, 31, 215-228.

Delpeuch, F., Maire, B., Monnier, E., \& Holdsworth, M. (2009). Globesity: a planet out of control. London: Routledge.

Dryzek, J. (2015). Deliberative engagement: the forum in the system. Journal of Environmental Studies and Sciences, 5, 750-754.

Ebrahim, S., et al. (2013). Tackling non-communicable diseases in lowand middle-income countries: is the evidence from high-income countries all we need? PLoS Medicine, 10, e1001377.

Ericksen, P. J. (2008). Conceptualizing food systems for global environmental change research. Global Environmental Change, $18,234-245$.

Evans, D. (2014). Food waste: home consumption, material culture and everyday life. London: Bloomsbury.

FAO. (2002). State of food insecurity in the world 2001. Rome: Food and Agriculture Organization of the United Nations.

FAO. (2014). State of food insecurity in the world. Rome: Food and Agriculture Organization of the United Nations.

Foley, J. A., et al. (2011). Solutions for a cultivated planet. Nature, 478, 337-342.
Foresight. (2011). The future of food and farming: final report. London: Government Office for Science.

Free, C. (2008). Walking the talk? Supply chain accounting and trust among UK supermarkets and suppliers. Accounting, Organizations and Society, 33, 629-662.

Furbank, R. T., Quick, W. P., \& Sirault, X. R. R. (2015). Improving photosynthesis and yield potential in cereal crops by targeted genetic manipulation: prospects, progress and challenges. Field Crops Research, 182, 19-29.

Garnett, T. (2014). Three perspectives on sustainable food security: efficiency, demand restraint, food system transformation. What role for life cycle assessment? Journal of Cleaner Production, 73, 10-18.

Garnett, T., et al. (2013). Sustainable intensification of agriculture: premises and policies. Science, 341, 33-34.

Godfray, H. C. J., et al. (2010). Food security: the challenge of feeding 9 billion people. Science, 327, 812-818.

Gottwald, F.-T., Ingensiep, H., \& Meinhardt, M. (2010). Food ethics. New York: Springer.

Goucher L, Bruce R, Cameron D, Koh SCL, Horton P (2017) Environmental impact of fertiliser embodied in a wheat-to-bread supply chain. Nature Plants, (in press)

Guinee, J. B., \& Heijungs, R. (2011). Life cycle sustainability analysis. Journal of Industrial Ecology, 15, 656-658.

Habermas, J. (1998). Between facts and norms. Cambridge: Polity.

Haddad, L., et al. (2016). A new global research agenda for food. Nature, $540,30-32$.

Hammond, R. S., \& Dube, L. (2012). A systems science perspective and transdisciplinary models for food and nutrition security. Proceedings of the National Academy of Sciences of the United States of America, 109, 12356-12363.

Helgason, T., Daniell, T. J., Husband, R., Fitter, A. H., \& Young, J. P. W. (1998). Ploughing up the wood-wide web? Nature, 394, 431.

Hellweg, S., \& Canals, L. M. (2014). Emerging approaches, challenges and opportunities in life cycle assessment. Science, 344, 1109-1113.

Helmsing, B., \& Vellema, S. (2011). Value chains, social inclusion and economic development. New York: Routledge.

Holdsworth, M., et al. (2014). African stakeholders' views of research options to improve nutritional status in sub-Saharan Africa. Health Policy and Planning. doi:10.1093/heapol/czu087.

Horton, P., Koh, S. C. L., \& Shi Guang, V. (2016). An integrated theoretical framework to enhance resource efficiency, sustainability and human health in Agri-food systems. Journal of Cleaner Production, 120, 164-169.

Ingram, J., Ericksen, P., \& Liverman, D. (Eds.). (2012). Food security and global environmental change. London: Routledge.

Ingram, J. S. I., et al. (2013). Priority research questions for the UK food system. Food Security, 5, 617-636.

IOM (Institute of Medicine) and NRC (National Research Council). (2015). A framework for assessing effects of the food system. Washington: The National Academies Press.

IPCC (2014). Climate Change 2014: Synthesis Report. Intergovernmental Panel on Climate Change.

Jackson, P. (Ed.). (2009). Changing families, changing food. Basingstoke: Palgrave Macmillan.

Jackson, P., \& Viehoff, V. (2016). Reframing convenience food. Appetite, 98, 1-11.

Jackson, P., Ward, N., \& Russell, P. (2009). Moral economies of food and geographies of responsibility. Transactions of the Institute of British Geographers, 34, 12-24.

Jacobsen, S.-E., Sørensen, M., Pedersen, S., \& Weiner, J. (2013). Feeding the world: genetically modified crops versus agricultural biodiversity. Agronomy for Sustainable Development, 33, 651-662.

Koh, S. C. L., et al. (2012). Decarbonising product supply chains: design and development of an integrated evidence-based decision support system - the supply chain environmental analysis tool (SCEnAT). International Journal of Production Research, 51, 2092-2109. 
Lachat, C., et al. (2014). Developing a sustainable nutrition research agenda in Africa in the years to come-findings from the SUNRAY project. PLoS Medicine, 11, e1001593.

Lamberth, C., Jeanmart, S., Luksch, T., \& Plant, A. (2013). Current challenges and trends in the discovery of agrochemicals. Science, 341, $742-745$.

Lang, T., \& Heasman, M. (2004). Food wars: the global battle for mouths, minds and markets. London: Earthscan.

Leck, H., Conway, D., Bradshaw, M., \& Rees, J. (2015). Tracing the water-energy-food nexus: description, theory and practice. Geography Compass, 9, 445-460.

Lenzen, M., Murray, J., Sack, F., \& Wiedmann, T. (2007). Shared producer and consumer responsibility - theory and practice. Ecological Economics, 62, 27-42.

Lesk, C., Rowhani, P., \& Ramankutty, N. (2016). Influence of extreme weather disasters on global crop production. Nature, 529, 84-87.

Li, W.-W., Yu, H.-Q., \& Rittmann, B. E. (2015). Reyse water pollutants. Nature, 528, 29-31.

MacMillan, T., \& Benton, T. G. (2014). Engage farmers in research. Nature, 509, 25-27.

Marlow, H. J., et al. (2009). Diet and the environment: does what you eat matter? The American Journal of Clinical Nutrition, 9, 699S-703S.

McMichael, A. J., Powles, J. W., Butler, C. D., \& Uauy, R. (2007). Food, livestock production, energy, climate change, and health. Lancet, $370,1253-1263$.

Milne, R. J. (2012). Arbiters of waste: date labels, the consumer and knowing good, safe food. Sociology Review, 60(S2), 84-101.

Mittal, A. (2009). The 2008 food price crisis: rethinking food security policies. UN Conference on Trade and Development. G24Discussion Paper series, available at: http://www.cntq.gob. $\mathrm{ve} / \mathrm{cdb} /$ documentos/agroalimentaria/065.pdf

Montgomery, D.R. (2007). Soil erosion and agricultural sustainability. Proceedings of the National Academy of Sciences, 104, 13268-13272.

Moomaw, W., Griffin, T., Kurczak, K., \& Lomax, J. (2012). The critical role of global food consumption patterns in achieving sustainable food systems and food for all. Paris: United Nations Environment Programme, Division of Technology, Industry and Economics.

Morgan, K., Marsden, T., \& Murdoch, J. (2006). Worlds of food: place, power, and provenance in the food chain. Oxford: Oxford University Press.

Murchie, E. H., Pinto, M., \& Horton, P. (2009). Agriculture and the new challenges for photosynthesis research. The New Phytologist, 181, $532-552$.

Murcott, A. (Ed.). (1998). The nation's diet: the social science of food choice. Harlow: Longman.

O'Rourke, D. (2014). The science of sustainable supply chains. Science, 344, 1124-1127.

OST. (2007). Tackling obesities: future choices. London: Office of Science and Technology.

Phalan, B., et al. (2016). How can higher-yield farming help spare nature? Science, 351, 450-451.

Pittelkow, C. M., et al. (2015). Productivity limits and potentials of the principles of conservation agriculture. Nature, 517, 365-368.

Popkin, B. M., Adair, L. S., \& Ng, S. W. (2012). Global nutrition transition and the pandemic of obesity in developing countries. Nutrition Reviews, 70, 3-21.

Premanandh, J. (2013). Horse meat scandal: a wake-up call for regulatory authorities. Food Control, 34, 568-569.

Probyn, E. (2000) Carnal Appetites: food sex identities. London: Routledge.

Reilly, J., et al. (2012). Using land to mitigate climate change: hitting the target, recognizing the trade-offs. Environmental Science \& Technology, 46, 5672-5679.

Rockström, J., et al. (2009). A safe operating space for humanity. Nature, $461,472-475$.
Rodenburg, J., et al. (2015). Do NERICA rice cultivars express resistance to Striga hermonthica (Del.) Benth. And Striga asiatica (L.) Kuntze under field conditions? Field Crops Research, 170, 83-94.

Searchinger, T., Edwards, R., Mulligan, D., Heimlich, R., \& Plevin, R. (2015). Do biofuel policies seek to cut emissions by cutting food? Science, 347, 1420-1422.

Shove, E. (2010). Beyond the ABC: climate change policy and theories of social change. Environment \& Planning A, 42, 1273-1285.

Shove, E., Pantzar, M., \& Watson, M. (2012). The dynamics of social practice. London: Sage.

Song, G., et al. (2016). CRISPR/Cas9: a powerful tool for crop genome editing. Crop Journal, 2, 75-82.

Soussana, J.-F. (2014). Research priorities for sustainable Agri-food systems and life cycle assessment. Journal of Cleaner Production, 73, $19-23$.

Stern, N. (2006). Stern Review on the economics of climate change. http://www.hm-treasury.gov.uk/independent_reviews/sternreview_ economics_climate_change/stern_review_Report.cfm

Stirling, A. (2015). Developing 'nexus capabilities': towards transdisciplinary methodologies. ESRC Nexus Network discussion paper: http://www.thenexusnetwork.org/wp-content/uploads/2015/06 /Stirling-2015-Nexus-Methods-Discussion-Paper.pdf.

Sukhdev, P., May, P., \& Müller, A. (2016). Fix food metrics. Nature, 540, 33-34.

Syers, K. et al. (2011) Phosphorus and food production http://www.unep. org/yearbook/2011/pdfs/phosphorus_and_food_productioin.pdf

Tenenbaum, D. J. (2008). Food vs fuel: diversion of crops could cause more hunger. Environmental Health Perspectives, 116, 254-257.

Tilman, D., \& Clark, M. (2014). Global diets link environmental sustainability and human health. Nature, 515, 518-522.

Tirado, M.C., Crahay, P., Hunnes, D. \& Cohen, M. (2012). Climate change and nutrition in Africa. SUNRAY review papers. https://www. globalcube.net/clients/ntw/content/medias/download/SUNRAY Climate_change_and_nutrition.pdf

Trudge, C. (2016). Six steps back to the land. Why we need small mixed farms and millions more farmers. Cambridge, England: Green Books.

UN. (2013). World population prospects: the 2012 revision. New York: The United Nations, Department of Economic and Social Affairs, Population Division, UN.

UNEP (2007). Synthesis Report: Sudan Post-Conflict Environmental Assessment http://www.unep.org/documents.Multilingual/Default. asp? ArticleID $=5621 \&$ DocumentID $=512 \& \mathrm{I}=\mathrm{en}$

UNEP. (2014). Assessing global land use. Paris: United Nations Environment Programme, Division of Technology Industry and Economics.

Warde, A. (2005). Consumption and theories of practice. Journal of Consumer Culture, 5, 131-153.

Watson, M., \& Meah, A. (2013). Food, waste and safety: negotiating conflicting social anxieties into the practices of provisioning. In D. Evans, A. Murcott, \& H. Campbell (Eds.), Waste matters: new perspectives on food and society (pp. 102-120). Oxford: WileyBlackwell.

Webster-Gandy, J., Madden, A., \& Holdsworth, M. (2012). Oxford handbook of nutrition and dietetics. Oxford: Oxford University Press (2nd edition).

WHO. (2001). World health report: reducing risks, promoting healthy life. Geneva: World Health Organization.

Woolf, S. H. (2008). The meaning of translational research and why it matters. Journal of the American Medical Association, 299, 211-213.

Zhang, X., et al. (2015). Managing nitrogen for sustainable development. Nature, 528, 51-58. 
Zollitsch, W., Winckler, C., Waiblinger, S., \& Haslberger, A. (eds) (2007). Sustainable food production and ethics. Wageningen: Wageningen Academic Publishers.

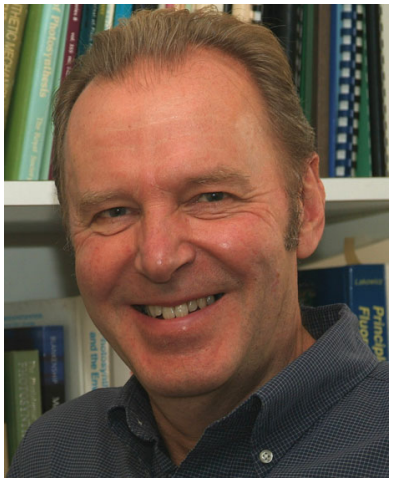

Peter Horton is Emeritus Professor of Biochemistry in the Department of Molecular Biology and Biotechnology at the University of Sheffield. Graduating with a BA in Biology in 1970, he holds a D.Phil. and D.Sc. all from the University of York. After postdoctoral training at Purdue University, he was appointed as Assistant Professor at the State University of New York at Buffalo in 1975. He then took up the post of Lecturer in Biochemistry at the University of Sheffield in 1978, was promoted to Reader in 1984 and to Professor in 1990. He was director of the Robert Hill Institute for Photosynthesis Research from 1989 until 2003. He was elected Fellow of the Royal Society (FRS) in 2010 in recognition of his research into the regulation of the light reactions of photosynthesis, particularly the molecular transformations that enable plants to efficiently use limiting light but dissipate excess light to protect themselves from damage during environmental stress, publishing over 200 peer reviewed papers in this field. He led two international agricultural projects, on abiotic stress in common bean in South America and on rice photosynthesis, in collaboration with the International Rice Research Institute in the Philippines. From 2008 to 2014 , he was research advisor to the University of Sheffield's Project Sunshine, the science behind food and energy sustainability and from 2015 until the present, Chief Research Advisor to the Grantham Centre for Sustainable Futures. As part of this role, he is helping develop an interdisciplinary research programme in food security.

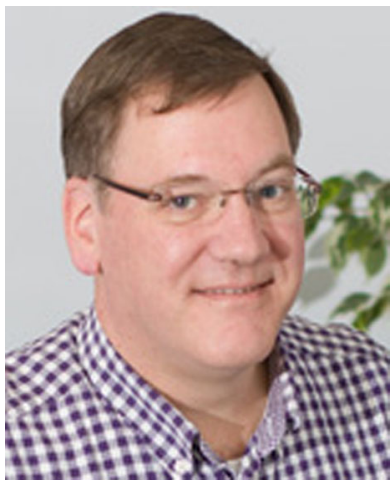

Steve A Banwart is Integrating Chair in Soil / Agriculture / Water Research at the University of Leeds. He holds an undergraduate degree in civil engineering and an MSc in environmental engineering from the University of Iowa, and a $\mathrm{PhD}$ in natural environmental sciences from The Swiss Federal Institute of Technology-Zurich. He was formerly Professor of Environmental Science in the Department of Geography at the University of Sheffield where he helped develop the University's sustainable food futures programme. He is also the academic leader of the theme on sustainable supply systems of the Northern 8 (N8) universities consortium $£ 16 \mathrm{M}$ agri-food research programme, jointly funded by the Higher Education Funding Council for England and the N8. He is an international leader in research on Earth's Critical Zone, the thin surface layer of the planet that supplies most life- sustaining resources. He led the EC Framework Programme 7 large integrating project Soil Transformations in European Catchments which established an international network of Critical Zone Observatories for soils research. He is an invited co-author of an emerging issues chapter Benefits of Soil Carbon published in the United Nations Environment Programme 2012 Yearbook. He led the Scientific Committee on the Environment international rapid assessment project on Benefits of Soil Carbon and is the lead editor of the resulting 400-page authoritative compilation of state-of-knowledge and innovation in policy and practices.

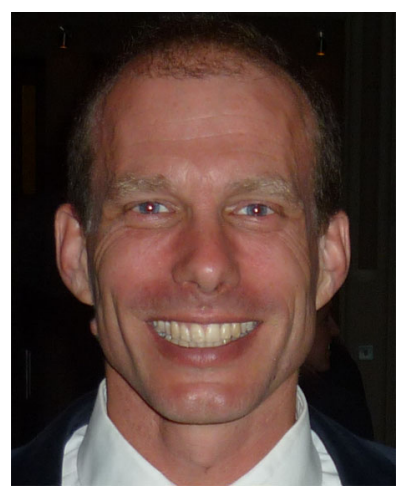

Dan Brockington is Director of the Sheffield Institute of International Development at the University of Sheffield. His research covers the social impacts of conservation, relationships between capitalism and conservation, the work of media and celebrity in development and long term livelihood change in East Africa. He has worked mainly in Tanzania and also South Africa, Australia, New Zealand and India as well as conducting global overviews of the social impacts of protected areas, media and conservation and continental wide examinations of the work of conservation NGOs in sub-Saharan Africa. Dan is happiest conducting long term field research in remote areas but also learns much from studying plush fundraising events. He has published Celebrity Advocacy and International Development and has also written Celebrity and the Environment, Nature Unbound (with Rosaleen Duffy and Jim Igoe) and Fortress Conservation and co-edited (with Rosaleen Duffy) Capitalism and Conservation.

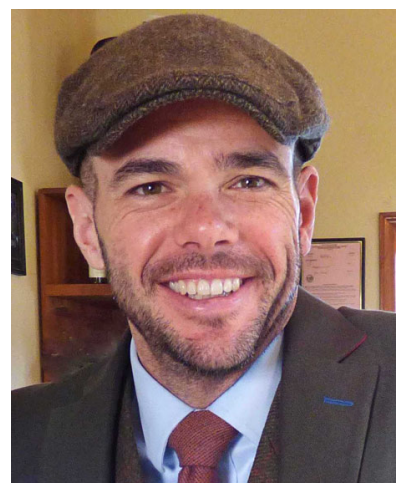

Garrett W. Brown is Reader of Global Ethics and Political Theory in the Department of Politics at the University of Sheffield. Graduating with a BA in Political Science in 1996 from the University of California Berkeley, he also holds a law degree from UC Berkeley Boalt School of Law as well as a MSc. and Ph.D. from the London School of Economics and Political Science. After holding postdoctoral positions at Queen Mary University and the London School of Economics, where he worked on mapping global institutions and governance, he became lecturer at the University of Sheffield in 2006 and is currently the Director of the Centre for Global Justice and Food Justice. He has published widely on issues of global distributive justice, global health policy, cosmopolitan ethics, international law and global governance. He has recently finished a three-year multi-country research project on global health financing mechanisms and has currently launched a five-year project titled Global Food Justice. 


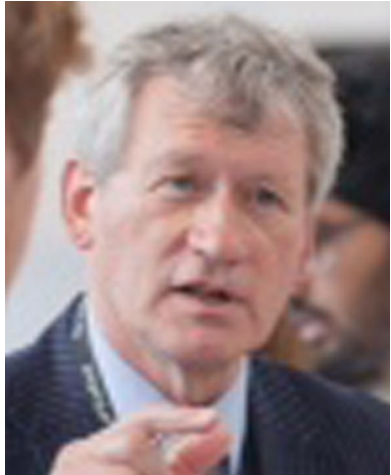

Richard Bruce has substantial experience of working with and developing global food supply chains, and has developed an extensive network across the sector. His in-depth first-hand knowledge of the supply-chain issues facing the global agri-food and FMCG sectors results from working across business in the UK and China, and in academia. He spent six years at Harper Adams University, where he established the DTI Enterprise Unit before founding his own business consultancy, working on strategic issues facing major suppliers and retailers, and interfacing with government and industry bodies. He is a Fellow of both the Royal Society of Arts and the Chartered Institute of Logistics and Transport. At The University of Sheffield, from where he holds a Masters Degree in Business Administration, he teaches supply chain accounting to Masters students, and is the Business Engagement Lead for the Grantham Centre for Sustainable Futures. His research examines the power-risk-trust triad in supplier relationships with retailers, and how those relationships are affected by the adoption of certain tools, such as open book accounting.

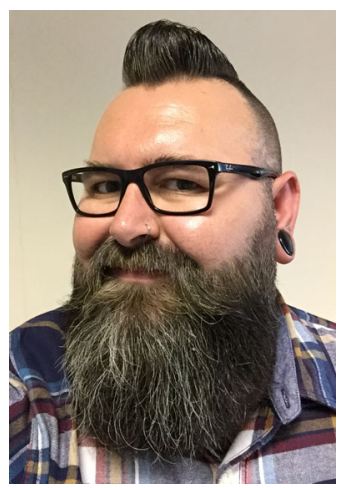

Duncan Cameron is Professor of Plant and Soil Biology in the Department of Animal and Plant Sciences at the University of Sheffield. He is co-director of the P3 Centre of Excellence for Translational Plant and Soil Biology. He currently holds a Royal Society University Research Fellowship at Sheffield where his group investigates the physiology and chemistry of plant-microbe interactions. After receiving his $\mathrm{BSc}$ in Biology from The University of Sheffield in 2001 and his PhD in Plant and Soil Science from The University of Aberdeen in 2004, Duncan undertook post-doctoral research in Sheffield and at the Julius von Sachs Institute, Würzburg, Germany. Duncan previously held a NERC fellowship (2007-2010). He was promoted to Senior Research Fellow in 2012 and to Professor in 2015. Duncan is subject editor of the journal Plant and Soil as well as a member of NERC's peer review collage. In 2013, he chaired the Royal Society Frontiers of Science meeting in Beijing, China and won the World Economic Forum's Young Scientist Award, awarded to "the best scientific minds who play a transformational role in integrating scientific knowledge and technological innovation to improve the state of the world" for his work on the microbiology of agricultural soils.

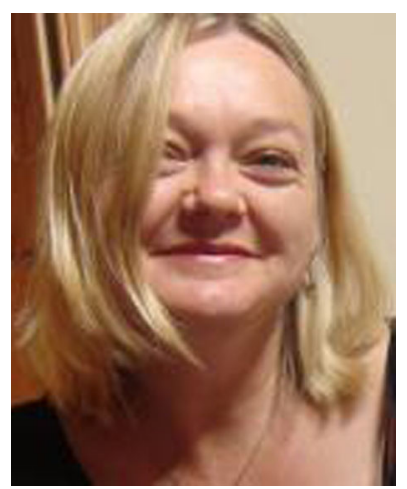

Michelle Holdsworth is a Professor of Public Health in the School of Health and Related Research (ScHARR) at the University of Sheffield. Graduating with a BSc in Food Science and Nutrition/Biology in 1985, and a PGDip in Dietetics in 1988, she also holds a $\mathrm{PhD}$ from the University of Sheffield. After 9 years working as a Community Dietitian and Food and Nutrition Policy Co-ordinator for the National Health Service, she undertook postdoctoral training at the Nutritional Epidemiology unit at the INSERM, Montpellier, France. She then worked as Assistant Professor and then Associate Professor at the University of Nottingham in the Division of Nutritional Sciences for 4 years. Before her appointment to the University of Sheffield in 2011, she worked for 8 years in Montpellier, France as a Senior Civil Servant Researcher - conducting research and capacity building work in public health nutrition, mainly in francophone Africa, for the Government funded Institute of Research for Development (IRD). She has significant research experience which has involved working in different cultural contexts (especially the UK, North Africa, sub-Saharan), falling broadly within three areas of public health nutrition: nutrition transition in low and middle-income countries, migration and its impact on diet, obesity policy development and integrating sustainability into nutrition policy. She is a Registered Dietitian (Public Health). She leads a multidisciplinary 'Food and Nutrition' research group in ScHARR.

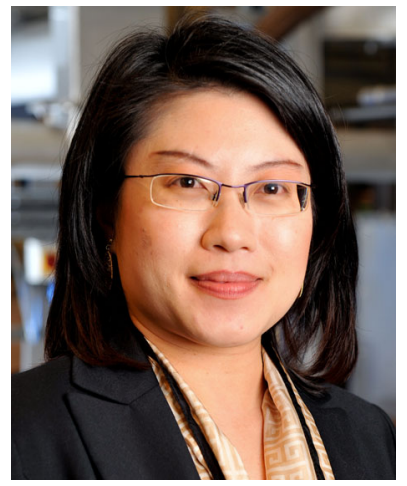

S. C Lenny Koh is Professor in Operations Management, Director, Logistics \& Supply Chain Management Research Centre, Director, Centre for Energy, Environment \& Sustainability and Director, Advanced Resource Efficiency Centre at The University of Sheffield. Her expertise includes supply chain management, particularly in low carbon futures/industries, low carbon supply chains, energy supply chains, environment and sustainability science, energy and resource efficiency, circular economy, and uncertainty management. With over 306 publications, she is involved in large scale projects funded by EPSRC, ESRC, EU, Innovate UK, BIS and The British Academy. She is Cross Cutting Chief for Supply Chain Resource Sustainability, and involved in the European Energy Research Alliance (EERA) on the Economic, Environmental and Social Impacts Joint Programme, specialising in Life Cycle Thinking. She chaired the Business Advisory Board of CLCF Low Carbon Supply Chain, consisting leading industry players such as Rolls-Royce, Tata Steel Europe, Unilever, Sheffield Forgemasters, Muntons, and led strategic research partnerships including the $£ 15.76 \mathrm{M}$ European Regional Development Fund Energy Innovation in Deprived Communities. She pioneered the development of the decision support system called 
SCEnAT used by leading industry. Externally, she is Chair of the Sustainability Partnership for Business, Innovation and Skills, working with government and industry.

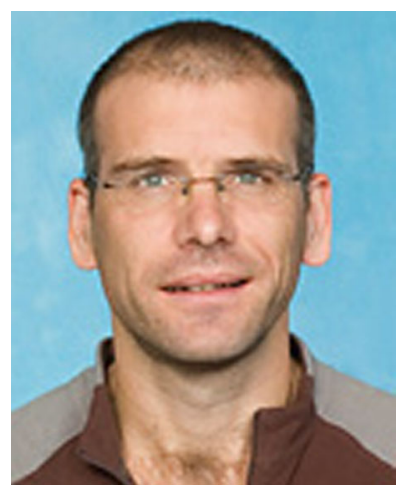

Jurriaan Ton is Professor of Plant Environment Signalling at the University of Sheffield. He holds an MSc (1996) and a PhD (2001) in Biology from Utrecht University, The Netherlands. After two postdoctoral positions at the University of Neuchâtel, Switzerland, he moved back to Utrecht University where he was awarded a NWO-VENI fellowship for Innovative Science to start his own research group. Four years later (2008), he moved to Rothamsted Research as a principal investigator (PI) on a BBSRC Institute Career Path Fellowship. In 2011, he took up a Lectureship at the University of Sheffield, where he was awarded an ERC consolidator grant in 2012. He is co-founder and co-Director of the $\mathrm{P}^{3}$ Centre for translational plant and soil biology at the University of Sheffield. He was promoted to Professor in 2015. His research focuses on the molecular and (epi)genetic basis of plant immunity, as well as the chemical signals mediating interactions between plants, microbes, and insects. In 2014, he was recognised as a highly cited researcher and member of 'the World's most influential scientific minds' by Thomson Reuters. He also holds a Research Leadership Award from the
Leverhulme Trust (2013) and receives additional PI funding from BBSRC and the EU.

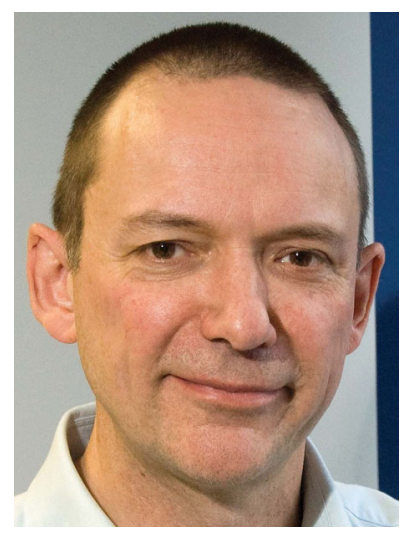

Peter Jackson is Professor of Human Geography at the University of Sheffield. Graduating with a BA in Geography in 1976 and a Diploma in Social Anthropology in 1977, he gained his DPhil from the University of Oxford in 1980. He was appointed Lecturer, then Senior Lecturer, at UCL before moving to Sheffield in 1993 where he has served as Head of Department (2000-3) and as Director of Research for the Faculty of Social Sciences (2004-7). He was elected Fellow of the Academy of Social Sciences in 2001 and received the Victoria Medal of the Royal Geographical Society in 2007. He directed the Changing Families, Changing Food research programme, funded by the Leverhulme Trust (2005-8), and was awarded an Advanced Investigator Grant from the European Research Council (2008-12) for a study of consumer anxieties about food. He is currently directing a project on Food, Convenience and Sustainability (2014-17) as part of an ERA-Net programme on sustainable food and an ESRC funded study of freshness in the UK and Portuguese agro-food sectors (20162018). Recent publications include Food Words (2013) and Anxious Appetites (2015), both published by Bloomsbury. Besides his academic research, he also advises the Food Standards Agency as Chair of their Social Science Research Committee. 